\title{
Context and Political Knowledge: Explaining Cross- National Variation in Partisan Left-Right Knowledge
}

\author{
David Fortunato, University of California, Merced \\ Randolph T. Stevenson, Rice University \\ Greg Vonnahme, University of Missouri, Kansas City
}

\begin{abstract}
We present a theory that links variation in aggregate levels of political knowledge across countries and over time to corresponding differences in the political context in which voters become (or do not become) informed. Specifically, we argue that the level of partisan left-right knowledge in a given context ultimately depends on how useful the left-right metaphor is for organizing, simplifying, or otherwise facilitating voters' understanding of political processes. Using survey data on the distribution of left-right knowledge in 59 different contexts (in 18 countries), our analysis reveals that voters understand the relative left-right positioning of parties to a much greater degree when these positions are important predictors of the composition of policy-making coalitions, but that variation in this knowledge does not correspond to the accuracy with which the relative left-right positions of parties predicts more narrow policy positions.
\end{abstract}

S urveys of British voters reveal that only about $56 \%$ of respondents can place the Labour Party to the left of the Conservative Party (Americans do about as well for the Republican and Democratic parties). In contrast, $86 \%$ of respondents to similar surveys in Denmark can place the Social Democratic Party to the left of the Conservative Party, $87 \%$ can place it to the left of the Liberals, and $82 \%$ can place it to the right of the Socialist People's Party. Indeed, almost half of Danish respondents can correctly order all 15 major party pairs. Such differences are apparent across the Western democracies and have a dramatic impact on political participation and ultimately the quality of representative democracy (e.g., Brady, Verba, and Schlozman 1995; Lazarsfeld, Berelson, and Gaudet 1948; Milbrath and Goel 1977; Milner

In this article, we seek to map and explain this kind of variation in knowledge about the relative left-right positions of political parties in the Western parliamentary democracies (we call this "partisan left-right knowledge"). We first describe a theory that links variation in aggregate levels of

political knowledge to differences in the political context in which individuals become (or do not become) informed. With this theoretical compass, we next describe an empirical project in which we construct a map of contextual variation in partisan left-right knowledge across a large number of countries and over a long period of time (59 electoral surveys drawn from 18 countries from 1992 to 2004). Finally, we use this map of partisan left-right knowledge and corresponding measures of political context to test the empirical implications of our theory.

Our theory begins with the rather uncontroversial idea that individuals learn to use abstract concepts like "leftright" for much the same reason they learn other similarly abstract concepts: these concepts have proven to be useful in organizing and understanding the world around them. This simple idea - that individuals will know and use an abstract concept when it proves useful for understanding and navigating the world-immediately implies an answer to the empirical question that motivates this project. If we observe large differences across contexts in the extent of partisan left-

David Fortunato (dfortunato@ucmerced.edu) is an assistant professor of political science at the University of California, Merced. Randolph T. Stevenson (stevenso@rice.edu) is a professor of political Sscience at Rice University. Greg Vonnahme (vonnahmeg@umkc.edu) is an associate professor of political science at University of Missouri-Kansas City.

Fortunato would like to acknowledge financial support from the Hellman Fellows Fund. Stevenson would like to acknowledge financial support from the National Science Foundation in the form of grant SES-0752362, Political Context and Political Knowledge in Modern Democracies. Data and supporting materials necessary to reproduce the numerical results in the paper are available in the JOP Dataverse (https://dataverse.harvard.edu/dataverse/jop). An online appendix with supplementary material is available at http://dx.doi.org/10.1086/686689.

The Journal of Politics, volume 78, number 4. Published online Month XX, 2016. http://dx.doi.org/10.1086/686689 
right knowledge, this likely springs from corresponding differences across contexts in the usefulness of that knowledge for understanding the political world. Thus, in this article, we argue that the level of partisan left-right knowledge in a given context ultimately depends on how useful the left-right metaphor is for organizing, simplifying, or otherwise facilitating voters' understanding of political processes. Where it is more useful for these purposes, elites will more often frame partisan politics in left-right language, and voters, both actively and passively, will come to have greater levels of partisan left-right knowledge. As Benoit and Laver tell us, "Political discourse is rather like a giant feral factor analysis. The concepts that emerge-liberal versus conservative, left versus right - emerge because people over the years have found them simple and effective ways to communicate their perceptions of similarity and difference" $(2012,198)$.

Thus, in broad strokes, our explanation of cross-national differences in partisan left-right knowledge isolates features of the political context that make the left-right metaphor a more or less effective way to communicate relevant similarities and differences about the parties. This approach closely mirrors the modern theory of heuristics promoted by Gerd Gigerenzer and his colleagues, who define a heuristic as a simple rule that maps a set of (limited) informational inputs into relatively complex inferences. Further, Gigerenzer argues that individuals are more likely to use heuristics (often subconsciously) to make "fast and frugal" inferences in situations in which doing so leads to correct predictions (on average, over populations). He calls such heuristics, and the people who use them in this way, "ecologically rational" (Goldstein and Gigerenzer 2002). Applied to our case, partisan left-right knowledge can be thought of as an input into a number of different partisan heuristics that individuals use to make inferences about different aspects of party politics. To take just one example, voters might use knowledge of the parties' relative left-right positions to make inferences about the likelihood of different policy-making coalitions.

Thus, one way to state our argument is as follows: Partisan heuristics will be more often used in political contexts in which it is "ecologically rational" to do so. Consequently, knowledge of their informational inputs (i.e., the parties' relative left-right positions) will be more pervasive in these contexts than in others. ${ }^{1}$

1. In section A of the appendix, we work out the details of the heuristic approach to our questions. However, since it is not strictly necessary to understand the thrust of our argument but requires that we explain a fair amount of background material on the general theory of heuristics and ecological rationality, we do not use this approach further in the main text.
However described, our explanation of variation in partisan left-right knowledge rests on corresponding variation in its usefulness across contexts. Thus, it is essential that we first understand the possible uses (or "functions") of partisan left-right knowledge for inferring or predicting important aspects of partisan politics. In the next section, we briefly review the large literature that has explored the possible functions of the left-right metaphor and identify three functions that are potentially relevant to cross-national variation in its usefulness for understanding partisan politics (or as as an input into partisan heuristics). Following that, we turn to the empirical challenge of measuring how well the left-right metaphor actually performs these functions in different national contexts and mapping this variation to corresponding variation in partisan left-right knowledge.

\section{THE FUNCTIONS OF PARTISAN LEFT-RIGHT KNOWLEDGE}

Our review of the relevant literature reveals three functions of the left-right metaphor that have garnered the bulk of scholarly attention: guiding voters' affective orientations toward the parties, summarizing or aggregating the relative policy positions of parties, and structuring the partisan composition of policy-making coalitions.

\section{Guiding affective orientations toward the parties}

One function of the left-right metaphor that is pervasive in both scholarly accounts and popular understanding is to guide voters' affective attachments to parties (we call this the affective function). Specifically, quite aside from any policy signals that parties' relative left-right positions might provide, left-right labels may be used by voters in the same way that they use party labels (often in the absence of much other information) to decide which parties they like (and how much they like them). Indeed, outside of the United States, where party attachments reign supreme, scholars often give primacy to this kind of ideological attachment over partisan ones (e.g., Dalton 2014). ${ }^{2}$

For example, Arian and Shamir argue that "for most people, left and right labels do not denote ideology and surely do

2. Many scholars of European politics have argued that voters' affective orientations to parties may be guided by left-right labels not because of any strictly "ideological" content (with its implicit connection to policy) but by deeper connections between left-right labels and social group identifications, i.e., "workers" identifying as leftist (e.g., Thomassen and Rosema 2009). Again, this parallels work in the United States that uses social identity theory to explain partisan attachments (see Huddy, Mason, and Aarøe [2015] for a helpful review). 
not reflect ideological conceptualization and thinking" (1983, 140). Instead, the left-right metaphor is "used to label and to identify the good or the bad, the right and the wrong, the desirable and the despicable" (142). In other words, quite apart from any specific policy content, when a party is on the "left" or "right," this tells the voter which other parties should be considered allies and which enemies. Taken one step further, it can allow the voter to know if a given party is in his/her "in" or "out" group — and by how much, with all the attendant emotional responses and perceptual and cognitive biases that give those categories force (see Aronson, Wilson, and Akert [2010] for a recent review).

\section{Aggregating policy positions}

By far the most discussed function of the left-right metaphor in partisan politics is to summarize a plethora of narrow policy positions into a more manageable, aggregated policy dimension and so provide voters with a policy-based means of orienting themselves toward the parties. Thus, voters who use the left-right metaphor in this way not only like or dislike parties (an affective orientation) but also can evaluate how close they are to each party in policy terms (and how close parties are to each other). We will call this the $a g$ gregative function. Todosijevic's contention, for example, is typical of the way many applied researchers emphasize this function when invoking the left-right metaphor: "Thanks to its absorptive nature, [the left-right construct] is able to represent a party's stands on various issues simultaneously" (2004, 411). Likewise, Knutsen suggests that "the use of the [leftright] schema is an efficient way to summarize the programs of political parties and groups, and to label important political issues of a given era" $(1995,63)$. And, of course, Downs famously asserted that "each party takes stands on many issues, and each stand can be assigned a position on our leftright scale" (1957, 132).

Overall, the vast majority of work that invokes the leftright metaphor in studies of partisan politics uses it for this aggregative function. That said, the relevance of this function for understanding individual political behavior in the real world has not gone unchallenged. Most damning is the empirical case that voters do not actually use the left-right metaphor for this purpose. The American Voter (Campbell et al. 1960) and Converse's (1964) influential essay, "The first round in a persistent attack on the idea that voters use the left-right (or, in this view, any similar metaphor) to understand the policy preferences of the parties or to orient their own preferences to these (see also Klingemann 1979). And, while the specific empirical evidence behind these conclusions has often been challenged (e.g., Nie, Verba, and Pe-

trocik 1976), the general picture of a public "with little comprehension of [the] ideological meaning [of the left-right]" persists, "even though 70 percent or more of the citizens in these mass electorates may use them to describe political parties" (Levitin and Miller 1979, 751).

While it is not our purpose to adjudicate this debate, the empirical results that we report later will bear on it. For now, however, we simply emphasize that despite the tendency of many scholars to treat the aggregative function of the left-right metaphor as essentially definitional (i.e., it is what the left-right dimension is), not all agree that this is the most important (or even an important) function of the construct in every context.

\section{Structuring policy-making coalitions}

In many political systems, parties can only make policy if they enter into policy-making coalitions with other parties. As such, one function of the left-right metaphor (though far less often invoked in the literature than the two discussed above) is in structuring voters' beliefs about which policymaking coalitions are likely to form, as well as their cognitive and/or affective orientations toward different coalition possibilities (we will call this the coalition function).

Importantly, this function can build on the policy aggregation function discussed above, or on the affective function, or on both. First, consider the situation in which the the left-right metaphor is an adequate summary of the parties' relative policy positions, so that it provides voters with policy information about parties. In that case, these leftright policy positions will also be a useful guide to the coalitional behavior of parties when, in a given context, the compositions of interparty policy-making coalitions depend on the policy compatibility (summarized by the left-right) of potential coalition partners. In this case, the left-right metaphor will be a useful guide to which policy-making coalitions are likely, what policies these coalitions will produce, and how much a policy-oriented voter will like that policyall of which are inferences that voters must make in many (policy-oriented) accounts of coalitional voting (e.g., Duch, Armstrong, and May 2010; Kedar 2005).

Of course, the coalition function does not require that voters understand the left-right metaphor as being mainly about policy. It could also be that a voter who use the parties' left-right positions to guide his/her affective partisan orientations (again, quite apart form any policy content) infers that parties similarly situated on the left-right (and for which the voter has similar affection) will be more likely to coalesce than more distant pairings. Further, such a voter can immediately translate his/her affective orientations toward the parties (as signaled by their left-right positions) to 
similar affective orientations toward different potential coalitions. $^{3}$

Arian and Shamir (1983) take this view in their argument that the left-right metaphor came to structure coalition politics in Israel even though it did not effectively aggregate the policy space. Specifically, they use a plethora of data to show that while Israeli voters relied more and more on partisan left-right labels over time, this was not because of increasing policy differences between the Israeli parties but because these labels were increasingly good indicators of party membership in broad political coalitions.

Regardless of whether one begins from an affective or policy interpretation of the left-right dimension, the coalition function will only be useful as a way to understand coalition politics if parties' left-right positions accurately predict which coalitions form (and, in the policy version, the policies these coalitions pursue). Of course, there is a great deal of such evidence in the literature on coalition formation and policy making (e.g., Martin and Stevenson 2001,

q9,q10 2010). Further, Fortunato and Stevenson (2014) have shown that voters' expectations about which party coalitions will form are strongly conditioned on their perceptions of the ideological congruence of potential partners. Finally, there is some evidence that the importance of the left-right in structuring coalitions is conditional on the institutional and political context in which they form and operate (e.g., Glasgow, Golder, and Golder 2012; Laver and Benoit 2015; Martin and Stevenson 2001)

\section{FROM FUNCTIONS TO KNOWLEDGE}

Having identified the three main functions of the left-right metaphor, the next step in our theory simply relates knowledge or use of this metaphor to variation in the usefulness of these functions across contexts. Specifically, we propose that the left-right metaphor will be more widely known, used, and understood in contexts in which it either more accurately predicts the relative left-right positions of parties on more narrowly defined issues and/or more accurately predicts which policy-making coalitions will form. That is, increasing the usefulness of these functions in a given con-

3. This implies an interesting, and to our knowledge unexplored, difference in the extent to which a policy vs. affective voter should like a coalition between two potential coalition partners that he/she locates to either side of his/her on the left-right dimension. Indeed, it is easy to construct theoretical situations in which parties are located such that the policy voter would prefer this coalition to all others (because it balances policy to produce a policy close to the voter) but where the affective voter would not, since the same idea of "balancing" is lacking in a purely affective left-right dimension (e.g., that only defines how much a voter likes parties, not their policy positions). text increases the relative value of partisan left-right knowledge for understanding relevant political processes in that context. Thus, by measuring, across contexts, variation in the accuracy of the aggregative and coalition functions of the left-right metaphor, we should be able to predict where (and when) partisan left-right knowledge will be widespread.

Before explaining how we measure variation in the usefulness of these two left-right functions, however, we first need to explain why we do not pursue a similar contextual hypothesis about variation in the first left-right functionguiding affective attachments to parties. The reason is that there is a clear difference between this function and the other two. Specifically, above we suggested that if a voter knows the left-right positions of parties (and his/her own left-right position), he/she can use this information in at least three ways: ${ }^{4}$

1. The voter can use this knowledge to orient himself/herself affectively to the parties (how much does this voter like each party?) [affective function]

2. The voter can use this knowledge to predict/infer the relative policy positions of parties (how close is this voter in policy terms to each party and the parties to each other?) [aggregative function]

3. The voter can use this knowledge to understand and predict the coalitional behavior of parties [ $\mathrm{CO}$ alition function], including:

(a) Which coalitions are likely to form

(b) Which polices different coalitions will produce

(c) Which coalition this voter will prefer

While each of these functions may be important in general (and we needed to explain all three to make our argument coherently), there is an important distinction between the coalition and aggregative functions on the one hand and the affective function on the other. Specifically, both the aggregative and coalition functions involve the voter inferring or predicting something about the behavior of the parties, while the affective function does not. This difference is crucial to what follows because it is variation

4. Obviously, he/she can also use this information to cast a vote, but that will always run through one (or more) of the three functions above. Specifically, sincere policy voting requires way 2 , sincere affective or symbolic voting requires way 1 ; strategic voting at the district level requires (along with some other knowledge) either way 1 or way 2 ; and strategic voting over coalitions requires (again with some other knowledge) either way 1 or way 2 along with way 3 . 
in the accuracy of those inferences across contexts that we argue makes the functions more or less useful.

Another way to put this is that in the last two functions, voters are using information about the left-right positions of parties heuristically - that is, as inputs into a simple rule that helps them to make more complex (or costly) inferences. In contrast, in the first function the voter draws no inferences. Thus, the ecological rationality of the affective function should not vary across contexts because of variation in the accuracy of the inferences that result from using it. In what follows then, we focus on the aggregative and coalition functions of the left-right, the accuracy of which we expect to vary across contexts.

In the next section, we will examine the two most important empirical implications of our theory: (i) differences in partisan left-right knowledge across contexts should be explained (in part) by corresponding differences in the reach or scope of the left-right dimension in organizing party positions across a large number of issues in those contexts and (ii) differences in partisan left-right knowledge across contexts should be driven by corresponding differences in how well the left-right positions of parties predict which policymaking coalitions form.

H1. Aggregative hypothesis: The better the relative general left-right positions of parties predict the relative positions of parties on more specific policies in a given context, the greater the level of partisan leftright knowledge among the voters in that context.

H2. Coalition hypothesis: The more accurately the relative left-right positions of parties predict the composition of policy-making coalitions in a given context, the greater the level of partisan left-right knowledge among the voters in that context.

Importantly, these are not mutually exclusive hypotheses-we may find support for one, both, or neither in the coming analysis. Further, if we do find differential support, this bears not only on the question of what drives differences in partisan left-right knowledge, but also on the relative salience of the aggregative and coalition functions of the leftright metaphor more generally. That is, the degree to which parties and political elites prioritize policy aggregation and coalition formation in the broader political discourse should determine the degree to which variations in the usefulness of the left-right metaphor for understanding these processes are manifest in the aggregate distribution of left-right knowledge. If understanding party positions on a large number of issues is most important, then variations in the aggregative function should drive variation in left-right knowledge. If understanding the formation of policy-making coalition is most important, then variation in the coalition function should drive variation in left-right knowledge.

\section{DATA ANALYSIS}

We begin with our dependent variable. To test our hypotheses, we examine data on citizens' knowledge of the ideological positioning of political parties, ${ }^{5}$ as reflected in 59 election surveys conducted in 18 developed parliamentary democracies (with similar socioeconomic attributes) from 1992 to $2004 .^{6}$ More specifically, we develop a measure of voters' knowledge about the left-right positions of parties that is comparable across voters, elections, and countries. Since this is one of the first times these kinds of data have been compared across a large number of countries and over a long time period, we spend some time discussing the various measurement decisions that we made and describing the extent and nature of the variation in our measures of partisan left-right knowledge. Thus, the section below sketches how we measured partisan left-right knowledge, defends that selection, and then provides a map of the variation in aggregate partisan left-right knowledge across countries and over time.

\section{Mapping differences in partisan left-right knowledge across countries and over time}

Our method of mapping variation in voters' partisan leftright knowledge proceeds in three steps. First, we identified 59 election surveys in 18 countries that asked voters to place themselves and their political parties on the left-right spectrum: ${ }^{7}$

In politics people sometimes talk of left and right. Where would you place [yourself/party X] on a scale from 0 to 10 where 0 means the left and 10 means the right?

5. In some of the analyses that follow, we treat Belgium as three separate cases, corresponding to whether a given survey targeted Flanders, Wallonia, or did not differentiate. Thus our 18 "countries" is only 16 if we consolidate all the Belgian cases. A complete list of all the countries and party dyads used in the estimations is provided in section $\mathrm{G}$ of the appendix.

6. Our case selection is motivated by two points. First, as the focus of our study is partisan left-right knowledge, we constrained our sample to countries with developed, stable party systems, omitting Europe's Central and Eastern post-communist countries, many of which were still transitioning to democracy over large swaths of our sample period. Second, we chose countries with comparable levels of wealth and education, leaving out poorer countries like Greece and Portugal.

7. Our data come from surveys administered by the Comparative Study of Electoral Systems (CSES) and the European Election Studies (EES) projects. 
Second, we assigned a "correct" left-right position to each

party to which we can compare voters' responses. ${ }^{8}$ Third, we transformed our respondent-party data into "respondentparty dyad" data (i.e., if $m$ is the number of parties, each respondent enters the data $m(m-1) / 2$ times, corresponding to every possible unordered pair of parties) and recorded, for each party-dyad, whether a respondent placed those two parties in the correct left-right order, the incorrect order, or said "Don't Know" for one or both parties. This threecategory variable is the main dependent variable in our analyses of the individual surveys.

There are a number of compelling reasons to focus on the ordinal placement of parties rather than their cardinal placement. First, our theory speaks to variations in the value of understanding the relative ideological positions of parties rather than their absolute positions. Second, a focus on the relative positions of parties drastically increases the extent to which different measures of the parties' "true" ideological positions agree with one another (as we discuss in the appendix, available online). This largely insulates our conclusions from an otherwise important source of measurement errorerror that is reflected in the (sometimes substantial) differences in absolute ideological placements of parties when ideology is measured in different ways (e.g., McDonald, Medes, and Kim 2007). Finally, our focus on the ordinal positioning of parties means that the cardinality of the ideology scales we use does not matter for our analysis - thus minimizing potential problems in comparing cases across contexts in which respondents may have systematically different definitions of what, for example, an "eight" on a left-right scale means.

The above sketch of our measurement procedure glosses over a number of thorny measurement issues that deserve more discussion than we can provide here. These issues include the following: which parties to include, what to do with "Don't Know" responses, and what to do with "tied" responses (where voters give both parties the same placement). We provide detailed discussion for interested readers in the appendix (sections $\mathrm{C}-\mathrm{E}$ ), but the short answer to these questions is that we include "important" parties (i.e.,

8. We explored four possible approaches to determining "true" party positions: the expert codings from the CSES survey modules, the Laver and Hunt (1990) and Benoit and Laver (2006) expert survey codings, estimates from the Comparative Manifestos Project, and then simply taking the mean ideological placement of each party, over all the respondents in a given election survey, the method suggested by Gordon and Segura (1997). We choose the final approach as it gives us an ordering for $100 \%$ of all party pairs in our data (the other methods vary from $40 \%$ to 97\% coverage) and because there is almost no variation in the rank orderings of party pairs across these four different methods, which, as we discuss below, is our focus. Interested readers may explore these data and our decision in more detail in section $\mathrm{F}$ of the appendix. excluding single-issue parties, regional parties, and very small parties), we model "Don't Know" responses explicitly, and we count tied responses as incorrect. Importantly, however, we have explored the robustness of our results to changing all of these decisions in various ways, and in no case do any of these decisions change the substantive results of our analysis.

With the above measures in hand, we can now turn to characterizing variation in partisan left-right knowledge across countries and over time. Figure 1 provides a detailed map of this knowledge across countries and over time by plotting the average percentage of correct rank-orderings in each of the surveys in our sample, organized by country and survey year. ${ }^{9}$ Since these are uncontrolled comparisons, we include only the percentage of respondents who correctly order the leading left and the leading right partythus maximizing the comparability of the dyads being compared across countries.

The dots are the estimated percentages, the line is the mean across surveys for the country, and the shaded area highlights the range between the maximum and minimum percentages across surveys in each country. Cases are sorted by the mean chance that leading left and right parties will be correctly ordered and range from a low of less than a $40 \%$ (Ireland) to a high of nearly $95 \%$ (Iceland). The main point of providing maps of contextual variation like this one is to visually assess the extent of variation that exists and whether this variation seems to be concentrated within countries, across countries, or both (see Duch and Stevenson 2008). A visual inspection of the graph reveals that the shaded areas (which give an indication of the extent of within-country variance) are small relative to the area spanned by the mean lines across charts. For countries in which we have two or more surveys, the average difference between the maximum and minimum survey is under $12 \%$, while, excluding Ireland, the difference between the maximum and minimum country mean is $35 \%$ (this is almost $60 \%$ including Ireland).

We can also formalize our parsing of the within-country versus between-country variance by estimating a multilevel model (with no covariates) in which we nest surveys within countries and estimate the cross-country variance separately from the within-country variance. Doing so reveals that over $66 \%$ of the total variance apparent in figure 1 is attributable to factors (measured or unmeasured) that vary across countries but are constant within countries. Likewise, $34 \%$ of the variance is attributable to factors that vary within countries.

9. This chart includes 59 cases, while the analysis reported below includes only 55 cases. This is due to some missing data exclusions (detailed in those analyses). 

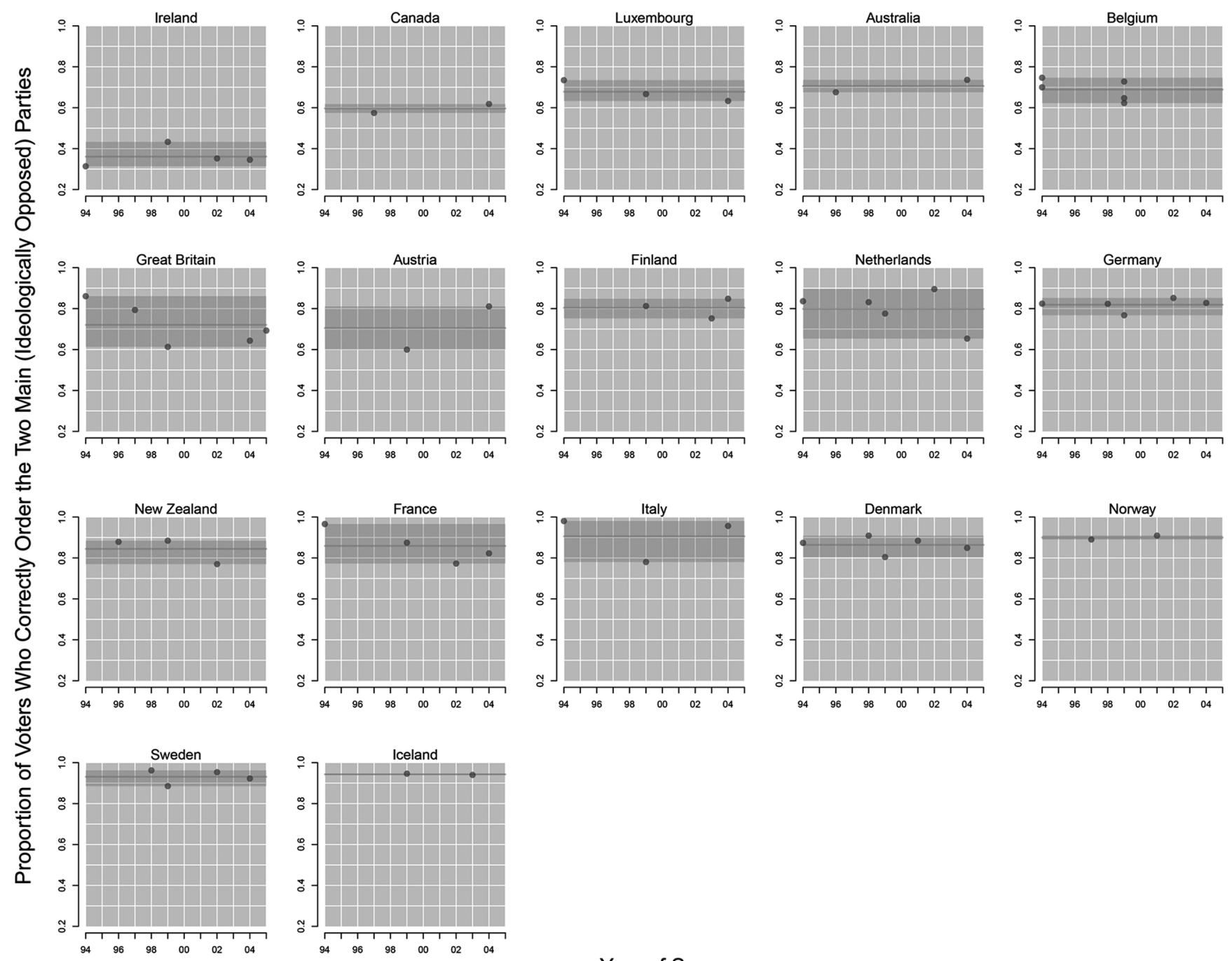

\section{Year of Survey \\ (Countries Ordered by Mean Proportion Correct)}

Figure 1. Map of partisan left-right knowledge across the Western parliamentary democracies

This suggests that there is substantial overall variation in the data and that between-country variation is dominant; thus, our search for explanations of this variation should focus first on contextual characteristics that are relatively unchanging over time but that vary across countries; the importance of parties' relative left-right positions to the composition of policy-making coalitions and the scope or importance of the left-right dimension as a policy aggregator are two such characteristics. That said, there is substantial within-country variation as well. Given the incremental pace of change in patterns of coalition formation and the dimensionality of political discourse, our theory does not provide a great deal of guidance on what might drive this within-country variance. Thus, we will want to tap into the rich literature that suggests other possibilities. This will provide not only a source of relevant controls that will help us make the main inference at which the empirical analysis is aimed but also the raw empirical material for fruitful extensions of the theory and tests of other theoretical perspectives.

There is one case, however, where we do observe a rather large change in the empirical regularities of coalition formation-New Zealand - as a function of a reform to its electoral system. We discuss this case in some detail after the main analysis as a type of robustness check on the findings we uncover.

\section{MEASURING THE KEY EXPLANATORY VARIABLES Variation in the aggregative function}

The aggregative function of the left-right metaphor allows voters to leverage knowledge of parties' general left-right positions to infer where a party stands on many different 
specific policies, such as social welfare (more or less generous programs), environmental protection (meticulous protection or loose oversight), or financial regulation (strict regulation or liberal deregulation). ${ }^{10}$

Consequently, if there is variation across contexts in the degree to which the parties' general left-right positions correlate with, or predict, their specific policy positions across salient policy issues, then we can say that the usefulness of the left-right metaphor stemming from this aggregative function will correspondingly vary. One way to think of this variation is as the policy "scope" or "reach" of the left-right metaphor in a given context, and it directly corresponds to how well variance in relative policy positions over parties in a given context can be explained by a single left-right dimension. ${ }^{11}$ For example, if knowing party A and party B's relative positions on the left-right dimension predicts their rank-ordering on most salient issues (and this holds for most party pairs in the system), then the left-right metaphor will be useful there. If, on the other hand, relative party positions on the left-right dimension are a poor predictor of positions on other issues in a given context, then the left-right metaphor will not be useful.

To test hypothesis 1 (the aggregative hypothesis) that leftright knowledge is driven by the scope or reach of the leftright metaphor in organizing policy positions across issues, we need a measure of how well the general left-right positions of parties in a country (over some period of time) predict their positions on other, narrower policy domains. There are several existing measures that get at aspects of this, and, since none is perfect, we examine our hypothesis with several different measures_-six, in all. Due to space constraints, however, we discuss only one in detail here-the measure we believe most closely captures our hypothesisand leave discussion of the rest in the appendix (section J). It is important to note, however, that all measures produce similar empirical results.

The measure we calculated is the average Spearman's rank correlation between the ordering of parties on the general left-right dimension and each of several specific policy

10. Notice that to make this inference, voters not only need to know parties' relative left-right positions but also have to understand how the general left-right dimension maps onto each policy-specific dimension. For example, to infer that a party $\mathrm{A}$ will favor a higher tax rate than party $\mathrm{B}$ requires not only that voters know party $A$ is to the left of party $B$ but that left parties tend to prefer a higher tax rate than right parties. Across a large number of issues, this mapping is a substantial informational burden that may undermine the usefulness of the aggregative function as a short-cut.

11. How many dimensions it takes to explain the remaining variance, after the left-right dimensions is accounted for, is a different question.
Table 1. Relative Importance of Left-Right to the Predicting of More Narrow Policy Positions

\begin{tabular}{lcc}
\hline Country & Estimate & Rank \\
\hline Germany & .501 & 1 \\
Austria & .449 & 2 \\
Australia & .446 & 3 \\
Norway & .428 & 4 \\
France & .425 & 5 \\
Sweden & .418 & 6 \\
Denmark & .414 & 7 \\
Luxembourg & .413 & 8 \\
Great Britain & .397 & 9 \\
Netherlands & .374 & 10 \\
Canada & .373 & 11 \\
Iceland & .351 & 12 \\
Italy & .336 & 13 \\
Belgium & .331 & 14 \\
Ireland & .328 & 15 \\
Finland & .254 & 16 \\
\hline
\end{tabular}

dimensions. To do this, we follow Lowe et al. (2011), who use the Comparative Manifestos Project data to define one general left-right policy domain and 14 more narrow policy domains in which specific party positions are calculated (these are about foreign alliances, militarism, internationalism, the European Union, constitutionalism, decentralization, protectionism, Keynesianism, nationalism, traditional morality, multiculturalism, labor policy, welfare policy, and education spending). The details of this measure (and all the others) are in the appendix, but the key idea is that it is higher when the Spearman correlations between the general left-right positions of parties and the 14 narrow policy dimensions are greater, indicating greater importance and/or scope of the left-right dimension. We calculated the measure for all the parties in the data for each country for the period spanning our survey data, 1992-2004, and we weighted the measure so that correlations on salient dimensions mattered more than correlations on less salient dimensions. We report the recovered values in table $1 .^{12}$

12. While we think that the best test of the aggregative power of the left-right should include whatever issue dimensions are salient in a country, we also constructed a version of this measure focusing only on "traditional" left-right issues (Keynesian economic policy, labor, and welfare). Clearly, these three issues are ones that we would expect to be ordered most consistently by the left-right. Even here, however, we find no consistent relationship between variation in the aggregative power of the left-right (over these three dimensions) and variation in political knowledge. These results are available in section $\mathrm{K}$ of the appendix. 
In terms of simple face validity, it is reassuring that our measure puts countries like Germany, Austria, Norway, and Sweden at the top of the rank-ordering (implying the relative left-right positions of parties best predict relative positions on more narrow policy dimensions) and countries like Finland, Ireland, Belgium, and the Netherlands toward the bottom. We think many comparativists with deep knowledge of the politics of these countries would recognize the sensibility of these relative positions.

\section{Variation in the coalition function}

To test hypothesis 2, the coalition hypothesis, we will need to estimate the extent to which the composition of policymaking coalitions depends on the relative left-right positions of parties in different contexts, a quantity we label

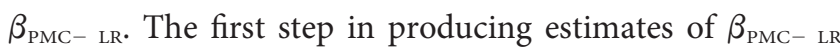
across different contexts is to clarify precisely what we mean by a "policy-making coalition." In our view, a policy-making coalition is a coalition that is sufficiently large (or otherwise empowered) to pass policy. In different countries the nature of these coalitions will differ. For example, in parliamentary democracies with high party discipline and single-party majorities, almost all policy-making coalitions will consist of all the members of the majority party in the legislature. In parliamentary systems with high party discipline and no majority party, policy-making coalitions will necessarily consist of all the members of two or more parties. Finally, in systems without high party discipline (e.g., the United States), policymaking coalitions may consist of various combinations of individuals drawn from different parties (including, in the United States, the president). ${ }^{13}$

In our sample - the high discipline, multiparty parliamentary countries plotted in figure 1-policy-making coalitions are equivalent (for the most part) to either single-party coalitions (i.e., coalitions of all legislators from a single majority party) or interparty coalitions (i.e., coalitions of all legislators from multiple parties). While it is certainly possible that such coalitions can shift issue by issue, in most systems this is not the case. Instead, in systems in which either a single party or a coalition of parties controls a majority of seats in the legislature, the composition of all policy-making coalitions is essentially equivalent to the party composition of the cabinet. Thus, for these cases, we can take advantage of the highly developed empirical literature on cabinet composition to facilitate the estimation of $\beta_{\mathrm{PMC}-\mathrm{LR}}$.

For cases in which the cabinet does not control a majority of seats in the legislature (i.e., cases of minority gov-

13. This is so except in cases in which the policy is passed by overriding a presidential veto. ernment), the party composition of policy-making coalitions can clearly vary from issue to issue, which, again, seems to necessitate an empirical model of the issue-by-issue composition of these coalitions, which no one has yet attempted. However, rather than eliminate cases of minority government from the analyses, we instead observe that in these cases, issue-by-issue policy-making coalitions are not really constructed out of all the various possibilities. Instead, these coalitions always include all parties in cabinet and only then add (perhaps shifting) noncabinet partners. ${ }^{14}$ Given this, it is not unreasonable to estimate $\beta_{\mathrm{PMC}-\mathrm{LR}}$ for these cases from an empirical model of cabinet composition (as we do for majority coalitions) - but we must remember that in these cases, the cabinet makes up only part (though the most stable and visible part) of any policy-making coalition. ${ }^{15}$

Thus, our measure of $\beta_{\mathrm{PMC}-\text { LR }}$ for each context will be estimated from appropriate empirical models of cabinet formation taken from the large and well-developed literature on that topic. Specifically, we rely on Martin and Stevenson's (2001) models of cabinet composition, which have largely shaped the subsequent empirical literature on the topic. To adapt these models to our purposes, there are three issues we need to address: (i) which of Martin and Stevenson's two models (one for the full set of potential cabinets and one that is conditional on the identity of the prime minister) should we adopt; (ii) how to estimate the variation of $\beta_{\mathrm{PMC}-\mathrm{LR}}$ across different contexts; and (iii) how to address countries in which one party usually wins a majority of seats in the legislature. We provide detailed discussion of these choices in section I of the appendix, but the short version is as follows. First, we estimate $\beta_{\mathrm{PMC}-\text { LR }}$ using versions of Martin and Stevenson's model 9, which takes the identity of the PM as given and asks what drives the selection of a specific set of cabinet partners. Second, we estimate a separate $\beta_{\mathrm{PMC}-\mathrm{LR}}$ for each country in our sample by estimating a mixed logit version of the Martin and Stevenson model that includes a random coefficient on the measure of the ideological spread of potential constellations of coalition partners relative to the given prime minister. From these estimates, we can then calculate empirical Bayes's predictions of the random coefficient for each country, which is our estimate of $\beta_{\mathrm{PMC}-\mathrm{LR}}$ for that country. Third, we set $\beta_{\mathrm{PMC}-\mathrm{LR}}$ to zero for cases in which only singleparty cabinets are observed over our sample period. Table 2

14. It is also the case that many minority cabinets are minority in name only-relying on a stable set of noncabinet partners to pass legislation.

15. Given this caveat, we have also estimated our models dropping countries in which minority cabinets are the norm, with no significant change to the results. 
Table 2. Relative Importance of Left-Right to the Selection of Coalition Partners

\begin{tabular}{lcc}
\hline Country & $\beta_{\text {PMC }- \text { LR }}$ & Rank \\
\hline Denmark & .086 & 1 \\
Sweden & .080 & 2 \\
Norway & .058 & 3 \\
France & .045 & 4 \\
Italy & .029 & 5 \\
Finland & .012 & 6 \\
Austria & .011 & 7 \\
Iceland & .011 & 7 \\
Germany & .010 & 9 \\
Ireland & .010 & 9 \\
Luxembourg & .009 & 11 \\
Netherlands & .007 & 12 \\
Belgium & .005 & 13 \\
Australia & .000 & 14 \\
Canada & .000 & 14 \\
Great Britain & .000 & 14 \\
\hline
\end{tabular}

shows the values recovered from our estimation sorted by rank. ${ }^{16}$ Although we are by no means the first to estimate a mixed-logit model of cabinet formation (e.g., Glasgow et al. 2012), we are the first to report the results of random coefficients estimated at the country level for the purpose of substantively useful cross-national comparison. ${ }^{17}$

Here again, we think that students of coalition formation in Western Europe would not find these results surprising (so providing some face validity to the measure). For example, we find that the left-right strongly structures the composition of cabinets in Scandinavia but not in the Low Countries, where ideologically disparate coalitions routinely form.

\section{Statistical models}

The data that we will use to test our hypotheses are, as described above, based on 55 election surveys. ${ }^{18}$ In developing appropriate empirical models, it is important that we first

16. The estimates of all other covariates accord well with those found by Martin and Stevenson, which are largely replicated by Glasgow et al. 2012.

17. The Glasgow et al. (2012) contribution focuses on introducing political science to the mixed-logit model for the primary purpose of dealing with IIA concerns. As such, the authors are more concerned with obtaining reliable estimates of the parameters and evaluating counterfactuals in general than in uncovering potentially interesting differences across specific contexts. Consequently, they estimate random coefficients at the level of the formation episode rather than at the country level.

18. Our original 59 surveys pictured in fig. 1 are reduced by the three New Zealand surveys and one of the Luxembourg surveys. These were omitted due to missing data in the independent variables. understand the relatively complex structure of the data. Table 3 illustrates this structure. In each survey, each respondent placed each of the parties in the election on a left-right scale or chose "Don't Know." We then turned these data into dyads, so that our dependent variable records whether each voter correctly or incorrectly ordered each dyad (or said they did not know for at least one of the parties). This means that each respondent enters the data $m_{j}$ times, where $m_{j}$ is the number of dyads in survey $j$. Likewise, each dyad within a survey, or "survey-dyad" enters the data $n_{j}$ times, where $n_{j}$ is the number of respondents to survey $j$. Thus, in the language of hierarchical data structures, the dyads and respondents are "crossed." In addition, dyads are crossed with surveys, as each party-dyad may appear in multiple surveys and each survey has multiple dyads. Finally, surveys are nested in countries, since each survey applies to one, and only one, country.

This data structure leads to six possible sources of both measured (fixed) and unmeasured (random) effects on the probability of our dependent variable obtaining one of its three possible values:

1. Country: effects that vary over countries but that are constant over surveys, dyads, and respondents within a country

2. Survey: effects that vary over surveys but that are constant over dyads and respondents within surveys

3. Dyad: effects that vary over dyads but that are constant over respondents evaluating a given dyad (even if these respondents are evaluating the dyad in different surveys)

4. Survey-dyad: effects that are constant over respondents evaluating a given dyad but that vary from survey to survey for the same dyad

5. Respondent: effects that vary over respondents but that are constant over all dyads evaluated by the same respondent

6. Dyad-respondent: effects vary from dyad to dyad for the same respondent (when this is unmeasured, it is the "residual" error)

Our first goal is to collect measures of concepts at each level that will be effective controls (i.e., that help us identify the causal effect of our key independent variables). After assembling an appropriate collection of control variables at these levels, we will turn our attention to statistically accounting for potential effects from unmeasured factors at these levels. It is critical not to ignore the possibility of such unmeasured factors since, at each level, these unmeasured 
Table 3. Structure of the Data

\begin{tabular}{|c|c|c|c|}
\hline Countries & Surveys & Dyads & Respondents \\
\hline Austria & EES 1994 & SPÖ-ÖVP & A \\
\hline Austria & EES 1994 & SPÖ-FPÖ & $\mathrm{A}$ \\
\hline Austria & EES 1994 & SPÖ-ÖVP & B \\
\hline Austria & EES 1994 & SPÖ-FPÖ & B \\
\hline Austria & CSES 1999 & SPÖ-ÖVP & $\mathrm{C}$ \\
\hline Austria & CSES 1999 & SPÖ-FPÖ & $\mathrm{C}$ \\
\hline Austria & CSES 1999 & SPÖ-ÖVP & $\mathrm{D}$ \\
\hline Austria & CSES 1999 & SPÖ-FPÖ & $\mathrm{D}$ \\
\hline Germany & EES 2004 & SDP-CDU & $\mathrm{E}$ \\
\hline Germany & EES 2004 & CDU-FDP & $\mathrm{E}$ \\
\hline Germany & EES 2004 & SDP-CDU & $\mathrm{F}$ \\
\hline \multirow[t]{2}{*}{ Germany } & EES 2004 & CDU-FDP & $\mathrm{F}$ \\
\hline & Dyads CROSSED with Surveys & & \\
\hline Surveys NESTED within Countries & & Respondents CROSSED with Dyads & \\
\hline
\end{tabular}

Note. CSES = Comparative Study of Electoral Systems; EES = European Election Study.

effects are constant across some "rows" of the data-thus, necessarily creating systematic correlations among our observations at each level.

\section{Accounting for measured and unmeasured factors}

We have data on a wide variety of control variables. The details of the variables that are used in the models reported here are described in the appendix (section $\mathrm{H}$ ) along with an overview of the various concepts we attempted to measure and the level of data hierarchy where their influences can be felt. In sum, at the individual level, we account for gender, age, education, and whether or not respondents place themselves between the parties they are evaluating. At the aggregate level, in addition to our focal variables, we account for the "true" ideological distance between the parties in the dyad, the number of parties in that country, the average time

q17 the parties in the dyad spent as PM, the average time they spent in cabinet but not serving as PM, whether or not the names of the parties are helpful to ideological placement (including, e.g., the word "left" for a left-leaning party), whether or not the names of the parties are harmful to ideological placement, the average size of the parties in the dyad, and the mode of the survey's administration (in person, telephone, or self-administered).

Moving on to unmeasured factors, in hierarchical data structures of the kind described above, the usual approach to dealing with unmeasured factors at each of the levels of the hierarchy is to estimate statistical models in which one assumes that the combined influence of all unmeasured factors at each level of the hierarchy is constant for that level (i.e., it impacts all observations at the level in the same way) and can be described as a realization of an appropriate random error. One then assumes a distribution governing the error terms at each level (usually a multivariate normalperhaps restricted to be independent) and estimates the parameters of this distribution to characterize the aggregate features of the errors at each level.

Such models have been used extensively in many disciplines and versions appropriate for an unordered categorical dependent variable are well understood. However, despite our ability to write down the statistical model most appropriate for our application, its complex, six-level structure (with several crossed levels) is far too complicated to estimate directly. Thus, a more creative strategy is necessary.

Our estimation strategy builds on literature arguing for a "two-stage" methodology when using multiple surveys to study the impact of context on political behavior (see Duch and Stevenson [2008] and the 2005 special issue of Political Analysis, which was devoted to the topic). Specifically, instead of stacking all the data from our 55 surveys, we use the following procedure:

1. Estimate individual multinomial logit models, with appropriate individual level controls, for each partydyad in each survey (a total of 394 separate estimations).

2. Use the estimated coefficients from these models to calculate the predicted probability that a typical voter in the survey correctly, incorrectly, or does not order the dyad.

3. Use these predicted probabilities, which sum to one over the three possible outcomes, as dependent var- 
iables in a linear, compositional, hierarchical model in which the independent variables are measured at the level of survey-dyads, dyads, surveys, and countries.

There are a number of compelling advantages to this approach over alternatives. First, like an approach in which one stacks the data, one gets estimates of the impact of any measured individual-level variables on the probability of each of our three outcomes. However, unlike stacking approaches, one gets separate estimates for each survey-dyad (the equivalent of interacting all individual-level estimates with surveydyad dummy variables in a stacked model), which can be presented directly or can be aggregated to characterize the general impact of individual factors on knowledge. More importantly, in the separate estimations, any characteristics of dyads (or of survey-dyads) that might cause respondents to systematically order correctly, order incorrectly, or not order the dyad are reflected in the estimates of intercepts in each separate model (and so are included in predicted values produced for each dyad). Thus, when we complete the firststage estimations, we have 394 three-element vectors of probabilities (that sum to one). For example, our estimate of these probabilities for the Socialist Left Party-Progress Party dyad in the 1997 Norwegian survey was 84\% Correct, 11\% Incorrect, and 5\% Don't Know. These vectors of probabilities then become the dependent variables in a second-stage, compositional model.

A compositional model is simply one in which the dependent variable is a vector of shares that sum to one. In our case, the "shares" are the estimated probabilities of each outcome for the average voter. ${ }^{19}$ Such models are now common in political science (e.g., Katz and King 1999) and are particularly useful in this setting, since (after an appropriate transformation of the dependent variable vector) they can be estimated using linear-normal statistical specifications, with which it is much easier to account for the remaining multilevel structure of the data. Specifically, one can take logratios of the vector of probabilities (choosing an arbitrary baseline category). This leaves a two-element dependent variable that can now be modeled using a (multivariate) normal distribution (i.e., a "seemingly unrelated regression").

To be clear, though we started with six levels of variation in the data, our separate estimation of multinomial choice models for each party-dyad is equivalent to estimating a

19. Note that the typical problems of estimated dependent variables do not apply here as sampling error does not vary substantially over observations and error components will be modeled hierarchically (see Lewis and Linzer 2005). party-dyad-level "random effects" model with random intercepts and random coefficients for all measured variables. ${ }^{20}$ Thus, the predicted values produced by these models already account for the respondent and respondent-dyad levels of variation, and the new data based on these predicted values have only four remaining levels of variation: surveys, dyads, survey-dyads, and countries. Since this eliminates two of the levels of the hierarchy in the data, and the estimation problem becomes much easier in the second stage where we estimate models allowing for random intercepts at the country, survey, and dyad levels.

\section{RESULTS}

In this section, we present some of the results from the estimation strategies detailed above. ${ }^{21}$ Before we turn to these results, however, we first present, in figure 2, a simple graph of the raw data relevant to our two main hypotheses.

The variable on the $y$-axis of both graphs is the proportion of respondents who are able to correctly rank-order the leading left and right parties in their system, the same values plotted in figure 1 . The $x$-axis on the left is the measure of the scope of the left-right dimension; the $x$-axis on the right is the country-specific measure of the importance of left-right in the structuring of policy-making coalitions. ${ }^{22}$ If both our hypotheses are correct, we should see a positive relationship between each measure and the percentage of voters ordering parties correctly. Clearly, however, there is only strong support for hypothesis 2 , the coalition hypothesis, in these plots. While the relationship in the left-hand graph is positive, it is only weakly so, especially compared to the strong positive linear trend on the right. But even more than that, figure 2 establishes the underlying evidence (and lack of evidence) that drives the estimates in the sta-

20. Recall that the least restrictive hierarchical model is simply groupby-group separate estimations.

21. Given the many alternative specifications discussed above, the results reported here are necessarily selections from these results. As we have repeatedly reported, however, our results are very robust to these many changes in specification. Many different estimates, however, are given in section $\mathrm{K}$ of the appendix.

22. Recall that the partner distance variable in the partner selection model was multiplied by -1 so that larger parameter values indicate a larger role for the left-right positions of parties in cabinet partner selection, and recall that we have set the value of this measure to zero for cases in which the only likely cabinets are single-party majority (Australia, Great Britain) or single-party minority cabinets (Canada). This is an appropriate value for countries in which the relative ideology of parties can play no role in selection of the executive (which is completely determined by the election result). Omitting these cases does not change our substantive results. To make the plots easier to read, we collapse the data in this figure to country means and omit the greatest outlier, Ireland, from the fitted lines. 

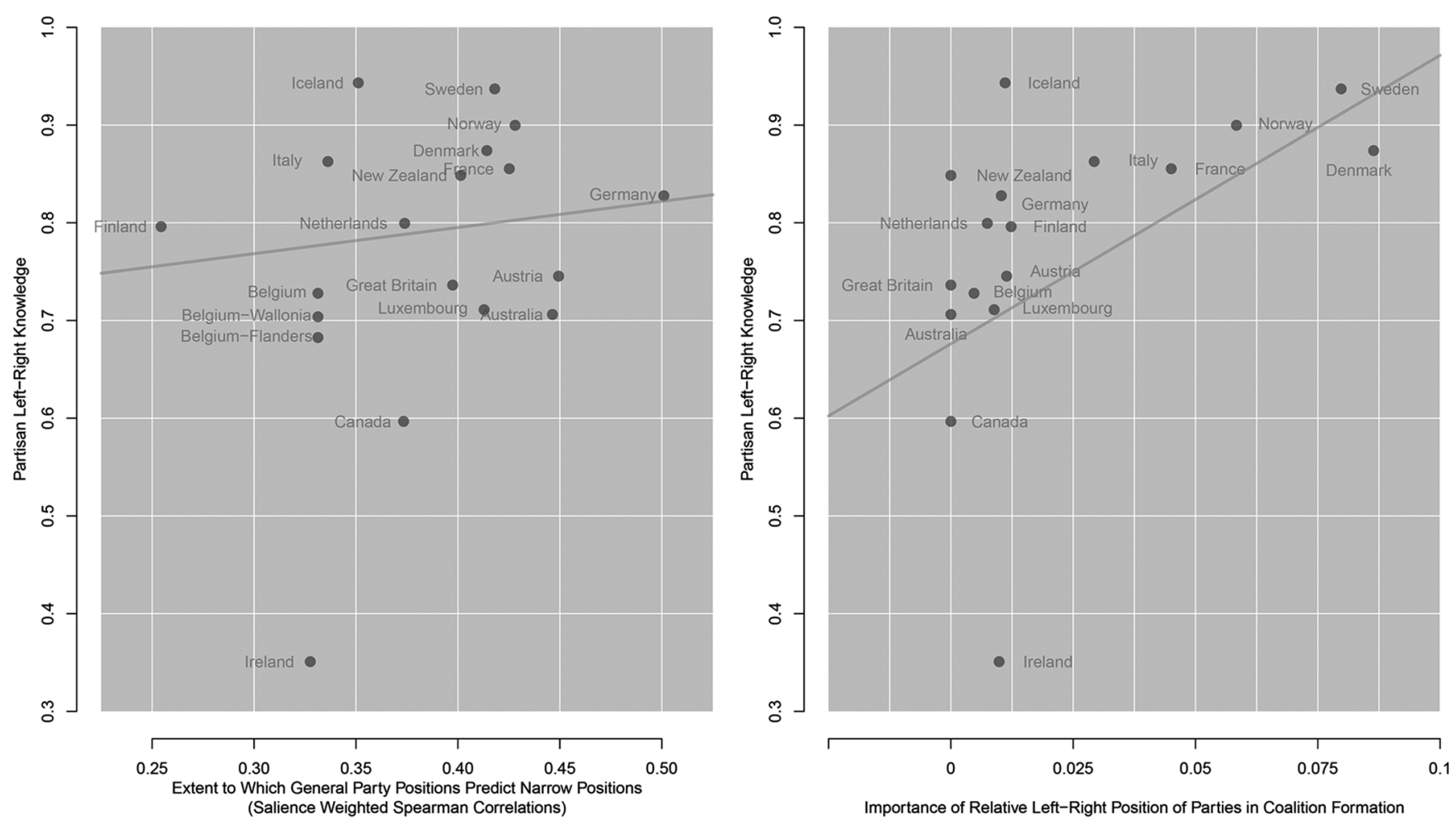

Figure 2. Evaluation of aggregative and coalition hypotheses with raw data

tistical models that follow. Indeed, one can think of all the elaborate modeling that we present below (as well as the many specifications described but not presented) as an attempt to see if we can do anything (sensible) to the specification of the models to change the relationship that is so obviously apparent on the right side of figure 2 and so obviously absent on the left. To preview: we cannot. The results below, as well as all our other results (available from the authors) using various sets of control variables, alternative measurements of some variables, alternative treatments of "tied placements," and different samples of parties all tell the same tale: the estimated effects of our measures capturing the coalition hypothesis are substantively large, never in the wrong direction, and always statistically significant, while the estimated effects of our measures capturing the aggregative hypothesis are substantively small, statistically insignificant, often of the wrong sign, and sensitive to model specification.

The estimated effects for our main model are presented in table 4 . This table presents the estimated change in the probability of ordering a "typical" dyad correctly, incorrectly, or saying "Don't Know" based on estimates from the "second-stage" model outlined above. We relegate all the estimated coefficients from this second-stage model to the appendix (section K), since coefficient estimates are not particularly informative about the substantive effects in the multi-equation, compositional models we are using. Instead, we report how the probability of each category changes when each variable moves between its 20th and 80th percentiles (dummies were changed from 0 to 1 ). Each estimated change in probability is calculated for a case in which each dummy variable is zero and other variables are at mean levels. Confidence intervals are simulated via parametric bootstrapping (King, Tomz, and Wittenberg 2000).

Before reviewing our focal variables, a few general observations are in order. The ideological distance variable is, of course, strongly significant and positive (we would be very concerned with our specification if it were not), indicating that respondents are better at ordering ideologically distinct parties than parties that are ideologically similar. In addition, it is encouraging that all the other control variables have estimated effects that are what one would expect. For example, dyads containing larger parties are easier to order than dyads with smaller parties and parties with names that provide clues to their location are easier to rank as well.

As for our hypotheses, clearly, the estimated impact of $\beta_{\mathrm{PMC}-\mathrm{LR}}$ is large and strongly significant, while the effect of differences in the scope of the left-right dimension is not. Further, the former effect is substantively larger than nearly all the other variables included in the model. On average, changing $\beta_{\mathrm{PMC}-\mathrm{LR}}$ as indicated above increases the probability of correctly rank-ordering the party-dyad by over 
Table 4. Substantive Effects for Second-Stage Variables

Change in Probability of Response:

Variable

Correct

Don't Know

Incorrect

Importance of left-right to selection of coalition cabinet partners $\left(\beta_{\mathrm{PMC}-\mathrm{LR}}\right)$

\begin{tabular}{ccc}
$.172^{\star}$ & -.013 & $-.160^{\star}$ \\
$(.073, .265)$ & $(-.096, .076)$ & $(-.229,-.083)$ \\
-.006 & .012 & -.006 \\
$(-.012, .000)$ & $(.000, .028)$ & $(-.015, .000)$ \\
$.191^{\star}$ & $.081^{\star}$ & $-.272^{\star}$ \\
$(.130, .252)$ & $(.025, .144)$ & $(-.310,-.236)$ \\
.018 & .000 & -.018 \\
$(-.0308, .064)$ & $(-.045, .053)$ & $(-.057, .023)$ \\
-.004 & .012 & -.008 \\
$(-.062, .053)$ & $(-.050, .076)$ & $(-.063, .045)$ \\
.006 & .055 & -.060 \\
$(-.080, .093)$ & $(-.044, .169)$ & $(-.143, .016)$ \\
.034 & .031 & $-.065^{\star}$ \\
$(-.022, .088)$ & $(-.018, .083)$ & $(-.109,-.021)$ \\
.038 & .021 & $-.06^{\star}$ \\
$(-.014, .091)$ & $(-.027, .068)$ & $(-.103,-.018)$ \\
.008 & .028 & -.037 \\
$(-.058, .071)$ & $(-.026, .088)$ & $(-.091, .014)$ \\
.048 & .048 & $-.096^{\star}$ \\
$(-.016, .115)$ & $(-.008, .107)$ & $(-.144,-.051)$ \\
.063 & .002 & $-.065^{\star}$ \\
$(.000, .124)$ & $(-.044, .054)$ & $(-.114,-.015)$ \\
\hline & &
\end{tabular}

Accuracy of left-right in predicting party position on narrow policy dimensions

Ideological difference between parties in the dyad

Number of dyads (parties) included in the survey

Telephone survey (base category is in-person interview)

Self-administered survey (base category is in-person interview)

Average time parties in dyad have been PM (not as PM)

Average time parties in dyad were in cabinet

Party names that might mislead respondent in ordering dyad

Party names that might help respondent in ordering dyad

Average size of parties in dyad

$(.000, .124)$

$-.044, .054)$

$-.114,-.015)$

Note. Number of countries $=18$; number of surveys $=55$; number of unique dyads $=187$; number of survey dyads $=394$. Cell entries are changes in probability when corresponding variable changes from its 20 th to 80 th percentile ( 0 to 1 for dummy variables) with $95 \%$ confidence intervals in parentheses. Note that if any one of the three compositional effects in a row is statistically different from zero, the the overall impact of the variable is statistically different from zero. The estimated parameters, as well as estimates of the random effects, are reported in the appendix.

* Statistically significant from zero at the XXX level.

$17 \%$, with the lion's share of the probability swing coming at the expense of incorrect responses. This means that respondents are not merely more likely to answer the question (perhaps feeling more emboldened to simply guess), but they are more likely to answer correctly. Of course, this supports the theoretical argument that contextual variation in the accuracy with which relative left-right positions predicts the formation of policy-making coalitions drives contextual variation in partisan left-right knowledge.

While the positive findings supporting the coalition hypothesis are expected, some may be puzzled by the lack of support for the aggregative hypothesis. There are three possible explanations for our null finding. First, it is possible that variation in the aggregative function of the left-right metaphor does, in fact, drive variation in left-right knowledge but that our measures of the cross-national variation in the usefulness of this function are simply too coarse to uncover this relationship - a possibility we believe to be unlikely given the close match of our operationalizations to the theoretical concept and the number of different measures employed (six in all) with no evidence of the predicted relationship. Second, it is possible that variation in the aggregative function of the left-right in our sample, though statistically robust, is insufficiently large in magnitude to uncover any potential influence on left-right knowledge across our 18 countries. That is, it is possible that the aggregative function is sufficiently important in all of our countries that it does encourage partisan left-right knowledge but that its usefulness simply does not vary enough across countries to drive the observed variation in this knowledge. Finally, it is possible that variations in the extent to which the relative left-right positions of parties structure their relative policy positions across a wide variety of issues does not impact the distribution of partisan left-right knowledge across contexts because this aggregative function is simply not as salient for voters (across all these contexts) as the coalitional function. 
Table 5. Substantive Effects for the Selected Individual-Level Variables from the First-Stage Models

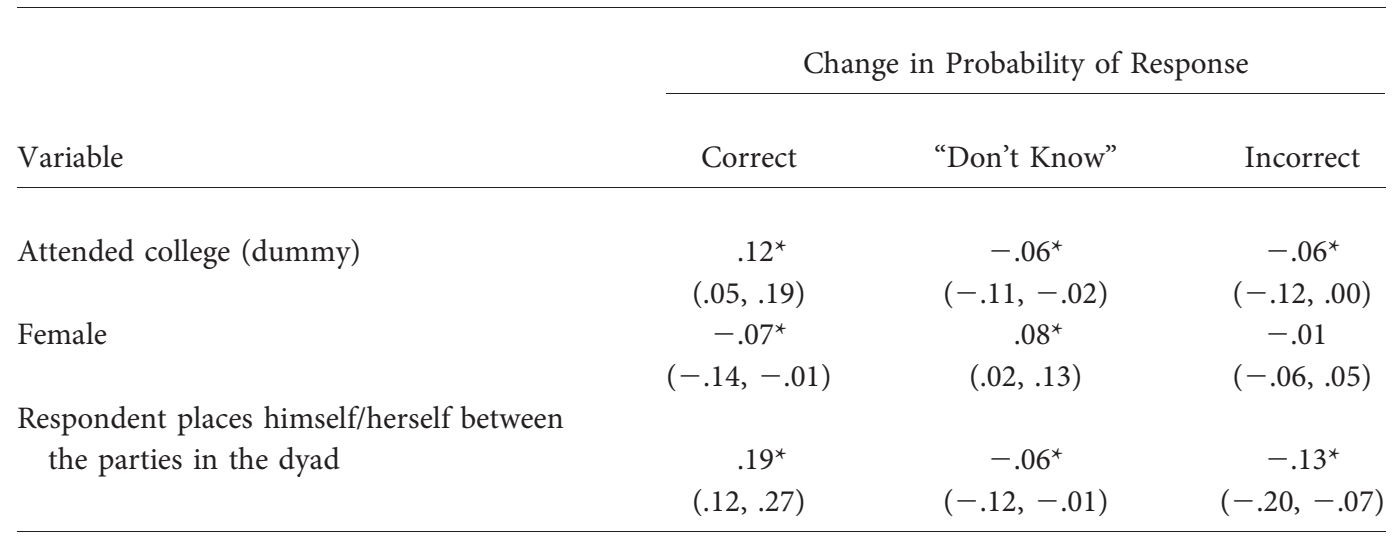

Note. Survey dyads (models) $=433$; total responses $=832,604$. Cell entries are changes in probability when corresponding variable changes from 0 to 1 with $95 \%$ confidence intervals in parentheses.

* Statistically significant (robust??) at the $\mathbf{X X X}$ level.

This is perhaps the interpretation favored by the large literature that doubts the salience of aggregative function of the left-right metaphor in general.

While our main interest is on the contextual variables that impacts partisan left-right knowledge, our results for some of the individual-level variables are also of interest. Table 5 presents aggregated effects from the results of our 433 separate estimates of several selected individual-level variables for each survey. ${ }^{23}$

The models tell us clearly that the effect of education (in this case a dummy variable for college attendance) has a strong effect on individual-level differences in political knowledge, as it should. The two other results are included because they provide some new information that should be of value to the literature on individual differences in political knowledge. The first is that our results strongly confirm the gender bias found in other studies of political knowledge and, for the first time, generalizes it to a wide set of modern democracies. Further, not only is the effect itself confirmed but there is also very strong evidence for the mechanism that has been suggested to explain this effect, that women are more willing to say "Don't Know" than men. Specifically, nearly the entire shift in probability due to being female (a quite large 8\%) moves between "Correct" and "Don't Know." Thus, in these data, women are less likely to be correct than men, but they are no more likely to be wrong. Instead, they are

23. These are the average change in probability (over all the separate estimates) for each category of the dependent variable when the relevant indicator variable changes from 0 to 1 . The confidence intervals were simulated for each of the separate models and then averaged for presentation in table 5. The difference in number of dyads (433 vs. 394) is attributable to missingness on the contextual variables. much more likely to say "Don't Know"-just as found by Mondak and Anderson (2004).

The second interesting finding here is that individuals who locate themselves ideologically between the two parties in the dyad are substantially more likely to correctly order the dyad than those who place themselves to the left or right of both parties. Indeed, the effect is about twice as large as having attended college.

\section{An illustrative investigation of New Zealand}

While we think that the cross-sectional evidence presented above is compelling, this evidence can be nicely supplemented by looking at situations in which the importance of the left-right metaphor in structuring policy-making coalitions has changed over time. We present a brief longitudinal investigation of New Zealand, which passed an electoral reform in the early 1990s resulting in a move from single-member district plurality to a mixed-member proportional system, beginning with the 1996 parliamentary elections. This change to New Zealand's electoral institutions fractured its party system, increasing the effective number of parties from 2 to 3.33, and resulted in a change from single-party majority governments - which New Zealand had had exclusively for almost its entire political history - to interpartisan coalition cabinets.

None of our measures of the aggregative function of leftright in New Zealand change significantly with the new electoral system. In contrast, though, the importance of leftright in structuring policy-making coalitions changed dramatically with the reform, going from nonexistent to substantively and statistically important (Brechtel and Kaiser 1999). This dramatic change in the structuring of policymaking coalitions, with no corresponding change in the ag- 
Table 6. Effect of Move to Coalition Government on Left-Right Knowledge in New Zealand

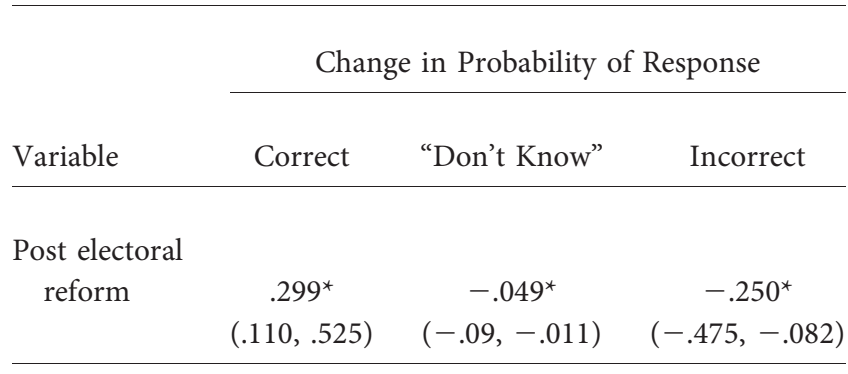

* Statistically significant at the XXX level.

gregative function of the left-right metaphor, allows for a uniquely controlled test of the coalition hypothesis. Specifically, if this hypothesis is correct, we would expect to see an increase in partisan left-right knowledge in New Zealand after the move to multiparty policy-making coalitions brought on by the electoral reform.

Our test is very similar to the main results presented above. We first gathered parliamentary electoral surveys from New Zealand for each election from 1990 to 2008, seven in total. With each survey we estimate a multinomial logit model of the probability that the respondents are able to correctly rank-order the leading parties (Labour and National) in the left-right space, where the dependent variable may take on a value of "correct," "incorrect," or "don't know" for each respondent. We include the same appropriate individual-level control variables discussed above. Using the results of each model, we predict the probability that a typical voter rankorders Labour and National correctly, incorrectly, or responds "don't know." To test our hypothesis, we need only evaluate whether the aggregate distribution of knowledge has shifted in the predicted direction, that is, to determine whether the typical New Zealander was better able to rank-order Labour and National after the reform than before. The most simple and direct way to test this, given our dependent variable, is to regress the predicted probabilities on a dummy variable indicating the post-reform period in a compositional model. ${ }^{24}$ Table 6 displays the predicted change in response probability derived from the compositional model, with confidence intervals calculated in the typical way.

The data suggest that the change from single-party majority cabinets to coalition cabinets brought on by the electoral reform had a robust positive impact on the aggregate

24. Note that because we are considering only one party-dyad, all of the second-stage control variables discussed above become superfluous. It is also worth noting that our sample size (only seven observations) makes the model unable to efficiently identify more than the two parameters (intercept and reform-period dummy) included. distribution of partisan left-right knowledge in New Zealand. Indeed, the probability of correctly rank-ordering the leading left and right parties increased nearly $30 \%$ after the change. These substantive results, though uncovered with only seven observations, are robust to sensible changes in coding and estimation, for example, alternating 1996 between pre or post periods, or stacking the data, rather than utilizing our two-stage approach. Taken together with the results presented above, the data provide very strong support for the coalition hypothesis: partisan left-right knowledge is driven by salience of relative left-right positions in structuring policy-making coalitions.

\section{DISCUSSION AND CONCLUSIONS}

In this article, we test the simple idea that individual knowledge about the left-right positions of parties in a given political context depends on the usefulness of that knowledge. We identified two functions of partisan left-right knowledge for predicting or inferring something about the behavior of parties - an aggregative function, which allows voters to infer the policy positions of parties on more specific policy dimensions, and a coalition function, which allows voters to predict the composition of policy-making coalitions - and showed that the usefulness of these functions varies across national contexts in sensible ways. This is, to our knowledge, the first such exploration of variation in these two functions across a large set of parliamentary democracies. We then asked whether cross-national variation in the usefulness of these functions could predict patterns of variation in the distribution of partisan left-right knowledge across contexts. To answer this question, we measured partisan left-right knowledge at the individual level using surveys from 59 election studies in 18 countries from 1992 to 2004 . The resulting map of partisan left-right knowledge is the first comparable, largescale description of differences in political knowledge across democratic systems, and so is itself a contribution to the empirical understanding of Western publics. ${ }^{25}$ Further, using this map of partisan left-right knowledge as the dependent variable in an empirical model of the impact of context on knowledge, we demonstrated (i) that variance in partisan leftright knowledge across contexts appears to be closely associated with the usefulness of the left-right metaphor in understanding the composition of policy-making coalitions, but (ii) that variance in partisan left-right knowledge across

25. That is, while several studies have attempted to measure variation in political knowledge, these studies have typically found themselves at the mercy of knowledge measures that are unsuitable for cross-national comparison. Questions, for example, that ask respondents to match photographs to names or names to cabinet posts are, for many reasons, incomparable across contexts and over time. 
contexts does not appear to be closely associated with the usefulness of the left-right metaphor in aggregating the policy positions of parties over different issues.

This null finding may be surprising to some readers, as many political scientists believe the aggregative function to be the primary function of the left-right. ${ }^{26}$ Nonetheless, it is important that readers do not misunderstand our findings. We are in no way claiming that the aggregative function is not important in Western parliamentary systems. Indeed, in constructing our measure of the scope of the left-right across our sample countries, we provide evidence that leftright positions do perform the aggregative function, and for the first time, we provide robust evidence that the importance of the left-right as an aggregator of policy stands varies substantially over these countries - a finding with very interesting potential implications. However, there is no evidence that this robust cross-national variation in the aggregative function of the left-right leads to greater or lesser levels of partisan left-right knowledge.

Our positive results on the effect of the coalition function in explaining variation in left-right knowledge complement previous findings in the large developing literature on "coalition-directed" voting. For instance, Duch et al. (2010), the most comprehensive cross-national investigation of coalition-directed voting to date, uncovers interesting contextual variation in the degree to which voters seem to weight (imputed) expected post-electoral bargaining outcomes in their vote choices. For example, Duch et al. find high levels of coalition-directed voting in Denmark, Germany, and Iceland but comparatively low levels in Ireland and the Netherlands. Our results uncover a possible explanation for this variation. Specifically, because coalition-directed voting, at least in most of its common formulations, requires voters to understand the relative left-right positions of parties and use that information to make predictions about both the likelihood of different cabinet combinations and the policy outputs of those combinations, it is no wonder that one finds more evidence of such voting where partisan left-right knowledge is more widespread.

More generally, our primary empirical finding, the discovery that enduring empirical regularities about coalitional politics influence the kind of political knowledge that elites are likely to provide and voters are likely to obtain, reinforces the clear connection between political context and behavior that has permeated the comparative literature in recent years,

26. Indeed, there is a long literature in American politics devoted to understanding how voters may use a partisanship heuristic to infer the preferences or likely behaviors of candidates across a wide array of issues. This is, after all, a special case of the aggregative function. succinctly summed up by Sniderman: "Citizens do not operate as decision makers in isolation from political institutions" (2000, 58). Like previous research on, for example, contextual variation in performance voting (Duch and Stevenson 2008; Powell and Whitten 1993), our results present strong evidence that variations in political context have a robust and far-reaching impact on the manner in which citizens engage politics, though this is one of only a handful of studies drawing an empirical connection between political context and political knowledge cross-nationally. ${ }^{27}$

Finally, our finding that partisan left-right knowledge varies predictably with features of the political context that mitigate the usefulness of that knowledge suggests that it may be profitable to investigate variation in other kinds of political knowledge in an analogous fashion. For example, in other work (Fortunato, Lin, and Stevenson 2015), we have demonstrated significant differences across countries in typical levels of knowledge about the composition of incumbent cabinets, the sizes of parties, and even which parties are politically active. Indeed, we hope that this study is the first step in constructing a comprehensive mapping of variation in political knowledge driven by contextual variation in political institutions and salient political processes. This kind of map will allow us to understand what an ideally informed electorate should know and what a reasonably informed electorate does know.

\section{ACKNOWLEDGMENTS}

The authors are grateful to Jim Adams, Courtenay Conrad, Ashley Leeds, Andrew Spiegelman, Federico Vegetti, and participants of the Political Behavior Research Group at the Central European University, as well as three anonymous reviewers and the editorial team, for their helpful feedback and guidance.

\section{REFERENCES}

Arian, Asher and Michal Shamir. 1983. “The Primarily Political Functions of the Left-right Continuum.” Comparative Politics 15 (2): 139-58.

Aronson, Elliot, Timothy D. Wilson, and Robin M. Akert. 2010. Social Psychology. 7th ed. Upper Saddle River, NJ: Prentice Hall.

Axelrod, Robert. 1970. Conflict of Interest. Chicago: Markham.

Benoit, Kenneth, and Michael Laver. 2006. Party Policy in Modern Democracies. London: Routledge.

Benoit, Kenneth, and Michael Laver. 2012. "The Dimensionality of Political Space: Epistemological and Methodological Considerations." European Union Politics 13 (2): 194-218

Brady, Henry E., Sidney Verba, and Kay L. Schlozman. 1995. "Beyond SES: A Resource Model of Political Participation." American Political Science Review 89 (2): 271-94.

27. Dimock and Popkin (1997), Gordon and Segura (1997), and Milner (2002) are standouts among this handful. 
Brechtel, Thomas, and André Kaiser. 1999. "Party System and Coalition Formation in Post-Reform New Zealand." Poltical Science 51 (1): 3-26.

Budge, Ian, and Michael Laver, eds. 1992. Party Policy and Coalition Policy in Europe. New York: St. Martins.

Campbell, Angus, Philip E. Converse, Warren E. Miller, and Donald E. Stokes. 1960. The American Voter. Chicago: University Of Chicago Press.

Converse, Philip. 1964. "The Nature of Belief Systems in Mass Publics.” In David Apter, ed., In Ideology and Discontent. New York: Free Press.

Dalton, Russel J. 2014. Citizen Politics: Public Opinion and Political Parties in Advanced Industrial Democracies. Washington, DC: CQ.

Downs, Anthony. 1957. "An Economic Theory of Political Action in a Democracy." Journal of Political Economy 65 (2): 135-50.

Duch, Raymond M., David A. Armstrong, and Jeff May. 2010. "CoalitionDirected Voting in Multiparty Governments.” American Political Science Review 104 (4): 698-719.

Duch, Raymond M., and Randolph T. Stevenson. 2008. The Economic Vote: How Political and Economic Context Conditions Election Results. New York: Cambridge University Press.

Fortunato, David, and Randolph T. Stevenson. 2013. "Perceptions of Partisan Ideologies: The Effect of Coalition Participation." American Journal of Political Science 57 (2): 459-77.

Fortunato, David, Nick C. N. Lin, and Randolph T. Stevenson. 2015. "What Voters Know in Coalitional Democracies." Unpublished manuscript, Rice University.

Glasgow, Garret, Matt Golder, and Sona Golder. 2011. "Who 'Wins'? Determining the Party of the Prime Minister." American Journal of Political Science 55 (4): 937-54.

Glasgow, Garrett, Matt Golder, and Sona N. Golder. 2012. "New Empirical Strategies for the Study of Parliamentary Government Formation." Political Analysis 20 (2): 248-70.

Goldstein, Daniel G., and Gerd Gigerenzer. 2002. "Models of Ecological Rationality: the Recognition Heuristic.” Psychological Review 109:7590.

q31 Goldstein, Daniel D., and Gerd Gigerenzer. 2011. "The Beauty of Simple Models: Themes in Recognition Heuristic Research." Judgment and Decision Making 6 (5): 392-95.

Gordon, Sarah, and Gary Segura. 1997. "Cross National Variation in Political Sophistication of Individuals: Capability or Choice?” Journal of Politics 59 (1): 126-47.

Huddy, Leonie, Lilliana Mason, and Lene Aarøe. 2015. "Expressive Partisanship: Campaign Involvement, Political Emotion, and Partisan Identity.” American Political Science Review 109 (1): 1-17.

Kedar, Orit. 2005. "When Moderate Voters Prefer Extreme Parties: Policy Balancing in Parliamentary Elections." American Political Science Review 99 (2): 185-99.

Klingemann, Hans-Dieter. 1979. "The Background of Ideological Conceptualization.” In Samuel H. Barnes, Max Kaase et al., Political Action. Beverly Hills, CA: Sage, 155-54.

Knutsen, Oddbjø rn. 1995. "Value Orientations, Political Conflicts and Left-Right Identification: A Comparative Study.” European Journal of Political Research 28 (1): 63-93.
Lazarsfeld, Paul F., Bernard Berelson, and Hazel Gaudet. 1948. The People's Choice. 2nd ed. New York: Columbia University Press.

Luebbert, Gregory. 1986. Comparative Democracy: Policy-making and Governing Coalitions in Europe and Israel. New York: Columbia University Press.

Laver, Michael, and Kenneth Benoit. 2015. "The Basic Arithmetic of Legislative Decisions." American Journal of Political Science 59 (2): 275-91.

Laver, Michael, and W. Ben Hunt. 1992. Policy and Party Competition. New York: Routledge.

Laver, Michael, and Kenneth Shepsle. 1990. "Coalition and Cabinet Government." American Political Science Review 84 (3): 873-90.

Levitin, Theresa E., and Warren E. Miller, 1979. "Ideological Interpre tations of Presidential Elections." American Political Science Review 73 (3): 751-71.

Lowe, William, Kenneth Benoit, Slava Mikhaylov, and Michael Laver. 2011. "Scaling Policy Preferences from Coded Political Texts." Legislative Studies Quarterly 26 (1): 123-55.

Martin, Lanny, and Randy T. Stevenson. 2001. "Cabinet Formation In Parliamentary Democracies.” American Journal of Political Science 45 (1): 33-50.

McDonald, Michael D., Silvia M. Medes, and Myunghee Kim. 2007. "CrossTemporal and Cross-National Comparisons of Party Left-Right Positions." Electoral Studies 26 (1): 62-75.

Milbrath, Lester W., and Madan L. Goel. 1977. Political Participation. Chicago: Rand McNally.

Milner, Henry. 2002. Civic Literacy: How Informed Citizens Make Democracy Work. Hanover, NH: University Press of New England.

Mondak, Jeff, and Mary R. Anderson. 2004. "The Knowledge Gap: A Reexamination of Gender-Based Differences in Political Knowledge." Journal of Politics 66 (2): 492-512.

Nie, Norman H., Sidney Verba, and John R. Petrocik. 1976. The Changing American Voter. Cambridge, MA: Harvard University Press.

Rieskamp, Jorg, and Philipp Otto. 2011. "SSL: A Theory of How People Learn to Select Strategies.” In Gerd Gigerenzer, Ralph Hertwig, and Thorsten Pachur, eds. Heuristics: The Foundations of Adaptive Behavior. Oxford: Oxford University Press.

Sniderman, Paul M. 2000. "Taking Sides: A Fixed Choice Theoryof Political Reasoning." In Arthur Lupia, Matthew D. McCubbins, and Samuel L. Popkin, eds., Elements of Reason: Understanding and Expanding the Limits of Political Rationality. New York: Cambridge University Press, 67-84.

Thomassen, Jacques, and Martin Rosema. 2009. "Party Identification Revisited," In John Bartle and Paolo Bellucci, eds., Political Parties and Partisanship: Social Identity and Individual Attitudes. New York: Rutledge.

Todosijevic, Bojan. 2004. "The Hungarian Voter: Left-Right Dimension as a Clue to Policy Preferences.” International Political Science Review 25 (4): 411-33.

Warwick, Paul. 1996. "Coalition Government Membership in West European Parliamentary Democracies.” British Journal of Political Science 26 (4): 471-99. 


\section{QUERIES TO THE AUTHOR}

Q1. AU: This article has been edited to conform to the journal's style regarding grammatical constructions, spelling, hyphenation. capitalization, use of italics or not, presentation of references and their citations in the text, and formatting of equations, figures, and tables, and the like. Please check the entire proof carefully to make certain than no changes of meaning or other errors have been introduced with these modifications.

Q2. AU: There is no reference for Verba et al. 1995. Provide same.

Q3. AU: By the journal's style, generally direct quotations of fewer than 100 words are run into the text rather than displayed in block form.

Q4. AU: This journal's style avoids one-sentence paragraphs. Your such has been combined with the following paragraph. Q5. AU: Isn't it the case that the three labels you give as examples are usually for the reverse, i.e. "right-left" rather than "leftright"?

Q6. AU: You originally wrote "Todosijevic, for example, is typical of ..." I have changed this to "Todosijevic's contention," since the statement was confusing in grammatical agreement, but please do substitute another word for "contention" or otherwise revise the statement to clarify the intended meaning.

Q7. AU: I have added the name of the essay here.

Q8. AU: This journal's style avoids the use of italics for placing emphasis. Your words italicized to that purpose have been changed to roman font.

Q9. AU: There is no reference for Martin and Stevenson 2010. Please provide same.

Q10. AU: The only reference for Fortunato and Stevenson has a date of 2013. Please reconcile.

Q11. AU: In footnote 4 you cited the items in the list below by putting their numbers in parentheses. This journal reserves numerals in parentheses exclusively for citing displayed numbered equations. I have done some rewording of footnote 4 to deal with this. Please check if this works for you and reword as needed - I find "way 1" etc. rather awkward. Also note that the list has been modified somewhat to avoid using "she" and "her" etc. Again, feel free to reword so long as your solution describes both genders.

Q12. AU: You had footnote citation numbers 5 and 6 together at the end of the sentence. The journal's style does not permit two such cites at the end of a sentence. I have moved the footnote 5 cite to earlier in the sentence. If this is not an appropriate placement please indicate a better placement for the two cites or indicate that the two can be comined into a single footnote with subsequent footnotes renumbered.

Q13. AU: The only reference for Laver and Hunt, listed in footnote 8, has a date of 1992. Please reconcile

Q14. AU: In the sentence that begins "Thus, we will want to tap ...," what is the referent of "possibilities"? The next sentence, which begins "This will not only provide ...," is grammatically confusing. Does "This" refer to "the rich literature"? How does the second part of the sentence relate to the first part? Please reword to clarify.

Q15. AU: Does PM stand for prime minister or something else? Also, clarify this with a definition for the table note for table 4.

Q16. AU: This journal does not use shading in its tables. When you have used it to indicate which variables are significantly significant (in some of the other tables), I have changed this to show that significance by our standard formatting. In this table 3, all of the shading has been removed. If the resulting table does not show what you indended it be mean, please redesign the table to do so by alternative means. Also, I have added a table note to this table with definitions of CSES and EES; please add to this note definitions of the acronyms in the Dyads column. It is not clear how the bolded entries in the last two rows of table 3 relate to the rest of the table's contents. If they were meant to be a key to the shading in the body of the table, please otherwise convey these distinctions in your table 3 redesign.

Q17. AU: PM = prime minister?

Q18. AU: There is no reference for Lewis and Linzer 2005 that is cited in footnote 19. Please provide same.

Q19. AU: There is no reference for Katz and King 1999. Please provide same.

Q20. AU: Can the shading be removed from figure 2? There is not enough contrast for the labels to show clearly.

Q21. AU: Again, this journal does not have shading in its tables. Table 4 is apparently depending on shading to indicate a level of significance. Instead we will use an asterisk to indicate this. I have added a single asterisk to each of the coefficients that had been shaded. Please revise the statistical significance note as appropriate.

Q22. AU: There is no reference for King, Tomz, and Wittenberg 2000; please provide same. 
Q23. AU: This journal requires that there be at least two of a given level of subhead. In this "Results" section you have only the one subsection, "An illustrative investigation of New Zealand." Please either indicate that this subsection level can be removed or identify another place in the "Results" section where a second subsection title can be placed or, perhaps best, indicate that this subsection can be turned into a full section.

Q24. AU: There is no reference for Powell and Whitten 1993. Please provide same.

Q25. AU: Dimock and Popkin (1997), cited in footnote 27, does not have a reference. Provide same.

Q26. AU: Axelrod 1970 is not cited in the text. Indicate where to cite or if to remove.

Q27. AU: Budge and Laver 1992 is not cited in the text. Indicate where to cite or if to remove.

Q28. AU: The Duch, Armstrong, and May article did not have a date, but I found it online.

Q29. AU: The only reference citation for Fortunato and Stevenson in the text has a date of 2014. Please reconcile.

Q30. AU: There is no reference citation in the text for Glasgow, Golder, and Golder (Glasgow et al.) 2011. Indicate where to cite or if to remove.

Q31. AU: Please note that the order of the authors has been changed to match what is on the article online. However, even with the names switched, there is no reference citation for this item in the text. Indicate where to cite or if to remove.

Q32. AU: There is no reference citation for Luebbert 1986 in the text. Indicate where to cite or if to remove.

Q33. AU: The only reference citation for Laver and Hunt has a date of 1990. Please reconcile

Q34. AU: Laver and Shepsle 1990 is not cited in the text. Indicate where to cite or if to remove.

Q35. AU: There is no reference citation for Rieskamp and Otto. Indicate where to cite or if to remove.

Q36. AU: Warwick 1996 is not cited in the text. Indicate where to cite or if to remove. 